\title{
Sphingolipid/Ceramide Pathways and Autophagy in the Onset and Progression of Melanoma: Novel Therapeutic Targets and Opportunities
}

\author{
Michele Lai ${ }^{1}$, Veronica La Rocca ${ }^{1}$, Rachele Amato ${ }^{1}$, Giulia Freer ${ }^{1}$ and Mauro Pistello ${ }^{1,2, *(\text { C }}$ \\ 1 Retrovirus Center and Virology Section, Department of Translational Research and New Technologies in \\ Medicine and Surgery, University of Pisa, 56127 Pisa, Italy \\ 2 Virology Unit, Pisa University Hospital, 56127 Pisa, Italy \\ * Correspondence: mauro.pistello@med.unipi.it
}

Received: 29 May 2019; Accepted: 8 July 2019; Published: 12 July 2019

check for updates

\begin{abstract}
Melanoma is a malignant tumor deriving from neoplastic transformation of melanocytes. The incidence of melanoma has increased dramatically over the last 50 years. It accounts for most cases of skin cancer deaths. Early diagnosis leads to remission in $90 \%$ of cases of melanoma; conversely, for melanoma at more advanced stages, prognosis becomes more unfavorable also because dvanced melanoma is often resistant to pharmacological and radiological therapies due to genetic plasticity, presence of cancer stem cells that regenerate the tumor, and efficient elimination of drugs. This review illustrates the role of autophagy in tumor progression and resistance to therapy, focusing on molecular targets for future drugs.
\end{abstract}

Keywords: melanoma; sphingolipids; ceramides; acid ceramidase; multidrug resistance; autophagy

\section{Introduction}

Melanoma is a malignant tumor deriving from neoplastic transformation of melanocytes, occuring at all anatomic sites where melanocytes can be found. Cutaneous melanoma generates from skin melanocytes and is the most common type of skin cancer, but it may also develop on mucous membranes and in the eye at a lower frequency [1,2]. The incidence of melanoma has increased dramatically over the last 50 years [3]. Although it accounts for $5 \%$ of all skin cancers, cutaneous melanoma is responsible for $75 \%$ of skin cancer deaths. Early diagnosis leads to remission in $90 \%$ of cases of melanoma because the tumor is located superficially and allows complete surgical removal. Indeed, surgical excision alone allows positive prognosis of over $90 \%$ of subjects with localized melanoma. Conversely, for melanoma at more advanced stages, prognosis becomes more unfavorable; the five-year survival rate from diagnosis varies between $60 \%$ and $24 \%$ according to the American Cancer Society. Advanced melanoma is often resistant to pharmacological and radiological therapies due to genetic plasticity, presence of cancer stem cells that regenerate the tumor, and efficient elimination of drugs. In this review, we will discuss the role of autophagy in tumor progression and resistance to therapy and examine a few metabolic pathways as potential targets to develop adjuvants or novel drugs overcoming resistance to therapy.

\section{Molecular Signatures of and Current Therapies against Melanoma}

Because of the intrinsic and remarkable ability of melanoma to develop resistance to therapy, intense efforts have been put to define novel approaches to treatment and pinpoint molecular pathways and signatures correlated to its progression. In this line of thought, the development of B-RAF inhibitors stemmed from the observation that the proto-oncogene B-Raf, encoding a serine/threonine protein 
kinase involved in cell signaling and directing cell growth [4], is mutated in a number of human cancers [5]. In addition, B-RAF mutations are present in benign nevi as well as in dysplastic ones, where the most common mutation is V600E [6,7]. B-RAF inhibitors showed adjuvant efficacy in combined treatment with standard chemotherapy in patients with melanoma; disappointingly, however, after less than six months, disease relapse was resistant to inhibitors, and consequently to therapy.

B-Raf is part of the mitogen-activated protein kinase (MAPK) cascade, which regulates complex cellular programs like proliferation, differentiation, development, transformation, and apoptosis [8,9]. It is therefore understandable why B-Raf plays a crucial role in the early stages not only of melanoma, but also in benign melanocytic neoplasms [10].

Recently, several lines of evidence indicate a pivotal role for the transcription factor associated with microphthalmia (MITF) in the onset of melanoma. MITF acts in the MAPK pathway, it regulates the development and differentiation of melanocytes, and it allows melanoblast survival [11,12]. Upregulated levels of MITF are associated with cell cycle arrest and differentiation, whereas downregulated levels lead to cell cycle dysregulation and apoptosis. Regulation of cell cycle by MITF is thought to occur primarily through interaction with $\mathrm{p} 16$ and p21 proteins, two onco-suppressors inhibiting cyclin-dependent kinases (CDK), and thereby triggering cell cycle arrest and apoptosis. Both onco-suppressors are frequently found mutated or deleted in primary tumors [13]. MITF, however, has multiple other roles, as it interacts with CDK2 and Bcl-2 proteins, promoting cell survival [11]; it also regulates transcription of ASAH1. As described in further detail in the following sections, ASAH1 encodes the enzyme acid ceramidase (AC) that controls sphingolipid metabolism and modulates the phenotypic switch of melanoma cells [14,15]. In melanoma, low levels of MITF are accompanied by low levels of ASAH1 expression, which correlates with invasive behavior and worse prognosis [11,12,15]. Furthermore, MITF knockout deranges the cell cycle and leads to cell death [15].

Another major player in the development of melanoma is phosphatidylinositol (PI)-3-kinase (PI3K) that regulates cell growth and survival, in combination with the factors mentioned above and others. Its pathway can be activated by Ras or by the loss of phosphatase tensin homolog (PTEN), encoded by the homonymous tumor suppressor gene, which is commonly expressed in melanoma cells. PTEN represses the PI3K pathway by dephosphorylating PI molecules. Growth signals increase intracellular levels of PI3 with a consequent phosphorylation and activation of protein kinase B (AKT) [16]. The increase in AKT expression found in melanoma is also observed in $50 \%$ of dysplastic nevi and $70 \%$ of metastatic melanomas [16]. In some $30-50 \%$ of melanomas, a loss of heterozygosity is described in the region of chromosome 10, where PTEN gene maps [17]. Inactivation of PTEN by deletion or mutation leads to constitutive activation of this pathway [16,17].

It is known that mutations of PTEN are rarely found in early stage melanomas [18,19], suggesting that activation of PI3K pathway is responsible for the development of late-stage melanoma, invasion, and metastasis [20]. Several studies show that mice with melanocytes presenting the above-mentioned V600E B-Raf mutation develop benign melanocytic hyperplasia that does not progress to melanoma until a subsequent mutation of PTEN transforms hyperplasia to fully malignant and metastatic melanomas [21]. This is probably why mutations of PTEN/ATK pathway occur later during tumor progression.

Melanoma therapy is mostly immunological, consisting of the administration of interleukin-2 (IL-2), unfortunately associated with toxicity and low response, or interferon- $\alpha$ (IFN- $\alpha$ ) which showed some benefits. However, among the chemotherapeutic agents approved for advanced melanoma, dacarbazine, carmustine, Taxol, and cisplatin showed some efficacy in the treatment of metastatic melanoma. Other theoretical or current therapeutic approaches focus on genes involved in cell proliferation that are found mutated in melanoma. Among them, N-RAS, the first oncogene identified in melanoma, and B-RAF are also considered important therapeutic targets because it has been shown that one-third of all human cancers have oncogenic mutations in the small GTPase RAS family, which may therefore play a pivotal role in tumorigenesis [22]. Among the first inhibitors developed, a RAS farnesyl-transferase inhibitor blocks the post-translational modification of RAS. This inhibitor is not effective as a single treatment but works well in combination with Cis-Platinum. The B-RAF inhibitor, 
vemurafenib, has been shown to be effective in the treatment of patients with advanced melanoma and V600E mutation. Unfortunately, this drug has a low genetic barrier to resistance, as this treatment becomes ineffective very soon after the first months of therapy in many patients [23]. The bottom line of melanoma therapy is not, therefore, the restricted number of therapeutic options, but rather the extraordinary ability of the tumor to acquire resistance to single and combined chemotherapy, a feature called multidrug resistance (MDR).

\section{Molecular Basis of Multidrug Resistance}

MDR in melanoma is a major obstacle for its successful treatment by chemotherapy. Inherent or acquired resistance of melanoma cells to cytotoxic compounds has been the subject of extensive research, which has elucidated different molecular mechanisms. The best understood examples in this respect is overexpression of the ATP-binding cassette (ABC) transport proteins, such as P-glycoproteins (P-gp), and the multidrug resistance-related proteins (MRPs) [24]. ABC proteins are capable of conveying a wide variety of substrates across cellular membranes, including chemotherapeutic drugs. Several studies have reported that inhibiting these transporters might reverse MDR [24-26]. This task is, however, difficult to achieve in melanoma cells because they express a wide variety of $A B C$ proteins, including $\mathrm{ABC} A 9, \mathrm{ABCB} 1 / 5 / 8, \mathrm{ABCC} 2$, and $\mathrm{ABCD} 1$, frequently found implicated, either alone or in combination, in the MDR phenotype $[27,28]$.

Despite the diversity in chemical structure and molecular targets, many (if not all) cytotoxic drugs eventually induce apoptosis. In principle, therefore, any cellular mechanism that hampers the apoptotic signal cascade may contribute to the strong resistance to chemotherapeutic agents exhibited by melanoma cells. Indeed, it is well established that low levels and activity of key apoptotic molecules, such as p53 and members of the Bcl-2 family, can determine chemoresistance [29,30], and novel therapeutic approaches are indeed focusing on restoring the activation of p53-dependent apoptosis [31,32].

\section{Sphingolipids and Ceramides}

Ceramides are a class of bioactive lipids that regulate senescence, apoptosis, and autophagy [33]. They comprise more than 200 chemically and functionally distinct molecules that can be produced through de novo synthesis or by cleavage of preformed sphingolipids [34-37]. The de novo pathway occurs on the cytosolic side of the endoplasmic reticulum by condensation of a serine and palmitoyl coenzyme-A by the enzyme serine palmitoyltransferase (SPT). This eventually leads to the formation of ceramides, after a series of reactions. The degradation pathway is carried out by sphingomyelinase (SMase) starting from sphingomyelin, whereas, in the recycle pathway, sphingosine is acylated by the enzyme ceramide synthase with the formation of C2-ceramide. Once ceramides are formed, various enzymes act to maintain their intracellular levels.

Ceramides are the most abundant cellular sphingolipids and important enhancers of the apoptotic program [14,33]. As shown in Figure 1, ceramides create a pro-apoptotic environment because they regulate cell cycle arrest, apoptosis, and senescence; these molecules are also implicated in inflammation, differentiation, and autophagic regulation. Administration of chemotherapeutic agents, such as daunorubicin, camptothecin, and etoposide, leads to the formation of ceramides [38-40]. Therefore, cellular control of ceramide levels may be a critical factor influencing drug resistance.

The conversion of ceramides into more complex molecules (e.g., glucosylceramides (GlcCer)) allows them to decrease their intracellular levels and, as a consequence, to block their pro-apoptotic modulation. Based on the observations that ceramides trigger apoptosis and that the lipid metabolism in most tumors is deranged [41], ceramides are considered tumor-suppressing molecules. In keeping with this idea, many MDR cell lines exhibit increased levels of GlcCer when compared to their drug-sensitive counterparts [42,43]. Since the in vitro finding has been confirmed ex vivo (e.g., in tumor biopsies), the level of GlcCer has been proposed as a clinical marker for MDR [44]. It should be noted, however, that lack of GlcCer synthase, which physiologically gauges the GlcCer level, does 
not sensitize melanoma cells for chemotherapy, suggesting that the accumulation of GlcCer occurs through other pathways as well [45].

Contrary to ceramides, sphingosine-1-phosphate (S1P) contributes to create an anti-apoptotic phenotype, favoring cell growth, cell motility, migration, and angiogenesis [46]. S1P, once secreted, acts as an autocrine/paracrine signal through the S1P receptors [47]. The activation of S1P receptor mediates cell survival, migration, and angiogenesis [48].

Ceramides and S1P have attracted considerable interest in cancer therapy over the years because they influence the response to chemotherapy and radiotherapy [49]. Several tumors enhance the metabolism of ceramides by increasing the production of enzymes such as GlcCer synthase, sphingomyelin synthase, ceramide kinase, and AC that convert ceramides into molecules with a lower pro-apoptotic impact $[14,15,49,50]$. Among these enzymes, ceramidases are frequently found overexpressed as they convert ceramides into sphingosine, thus indirectly increasing S1P levels and transforming a pro-apoptotic signal into a cell survival one [15].

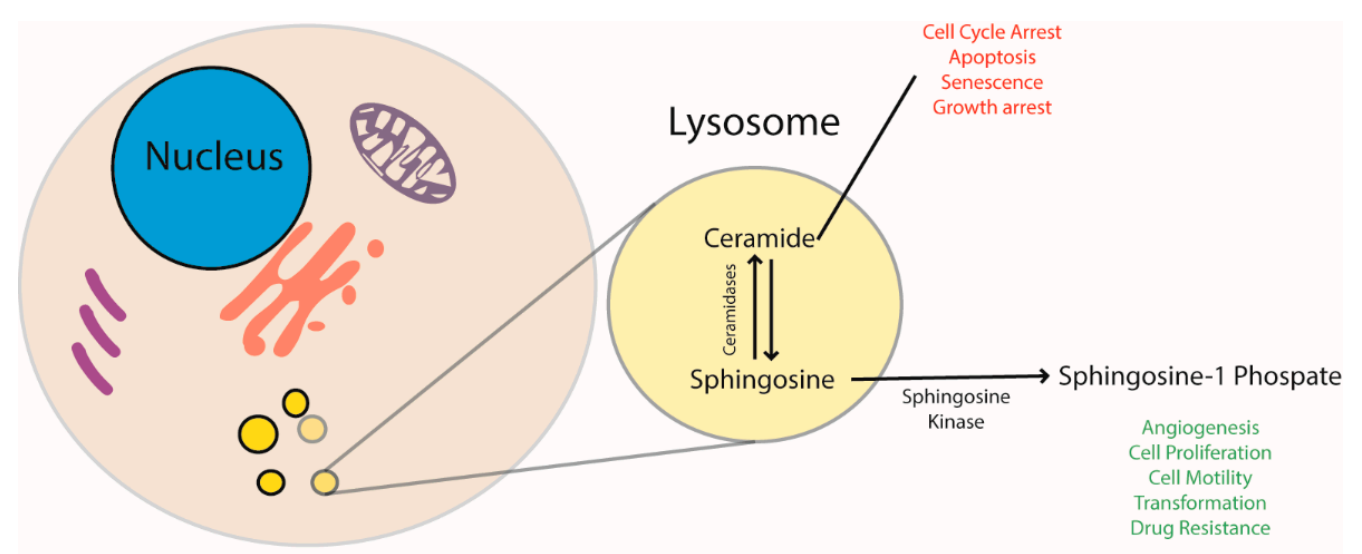

Figure 1. Ceramide and sphingosine-1-P regulate and stimulate opposite cellular pathways. The former has a pro-apoptotic effect and blocks cell replication, the latter stimulates cells to proliferate. AC balances ceramides and sphingosine levels. Since sphingosine is then converted to sphingosine-1-P by sphingosine kinase, AC has a direct role in regulating cell life.

\section{Sphingolipid Metabolism and Cancer}

Sphingosine and ceramide generation is induced by cellular stress through the activation of de novo synthesis pathways, the hydrolysis of sphingomyelin, and by the salvage pathway to mediate pro-apoptotic stimuli [51]. Many tumors, including melanoma, increase ceramide metabolism mainly by the activity of GlcCer synthase, sphingomyelin synthase (SMS), ceramide kinase (CERK), and AC. Overall, these enzymes generate sphingolipids with pro-survival functions [52]. Ceramides are divided based on the number of carbons that compose the fatty acyl chain, ranging from 14 to 26. The de novo synthesis of ceramide by (dihydro)ceramide synthases generates ceramides with different fatty acyl chains that have different biological roles in cancer cells, for mechanisms that are still unclear. It is possible that these different biological activities depend on the differential subcellular localization in normal/cancerous cells. The conversion of sphingosine to ceramide is catalyzed by the salvage pathway. Interestingly, these reactions involve the same enzymes of the de novo ceramide synthesis. The ceramidase activity, together with the sphingosine kinase 1 and 2, converts ceramides to sphingosine-1-phosphate. This bioactive lipid is further hydrolyzed by S1P lyase to exit the sphingolipid metabolic circle. Ceramides are also a substrate to generate complex sphingolipids such as gangliosides and glycosphingolipids [53]. In these reactions, ceramides are first converted into glucosylceramides, which are the precursors needed for the synthesis of complex sphingolipids. Interestingly, patients with Gaucher disease, which is an autosomal recessive genetic disorder caused by mutations of the lysosomal glucocerebrosidase enzyme, have a higher risk (37-fold) to develop myelomas compared to the general population [54]. Moreover, it seems that these patients 
have increased chances of developing multiple consecutive cancers in their lifespan. It is still unclear if defects in the glucocerebroside metabolism may be involved in the development of melanoma [55].

\section{Autophagy}

Since apoptosis contrasts MDR, drugs triggering programmed cell death in MDR cancer cells would be valuable. Unfortunately, the variegated pathways and triggers tweaked by melanoma cells to inactivate apoptosis add considerable complexity to the development of such drugs.

A potentially exploitable mechanism to interfere with MDR is autophagy. Autophagy is a finely regulated mechanism that degrades damaged cellular material and converts catabolites into nutrients and precursor compounds for the cell. Through this process, cells ensure basal turnover of cellular organelles and constant supply of energy and macromolecular precursors [56]. Active autophagy is also named autophagic flux as it occurs as a continuum; this process can be distinguished in several phases, such as formation of the phagophore and the autophagosome, and lysosomal fusion. Autophagy has been described in several articles that thoroughly discuss the roles of many proteins and lipids [57-59], which are actively involved in each of the stages. Here, we will briefly discuss the core pathway.

Autophagy is induced in response to various stress stimuli, such as starvation, reactive oxygen species, hypoxia, infection, and drugs. What causes the initial step that leads to the formation of the phagophore is still mostly unclear.

\subsection{Phagophore Formation}

This is an initial event following autophagy induction. Phagophore is a small cup-shaped membrane whose origin has been a matter of debate for years. Recent evidence indicates that the lipid membranes forming the autophagosomes are generated through a mechanism directed by autophagy-related (ATG) proteins that are located in the cytoplasm. Over 15 ATG proteins take part in autophagophore formation. Another important player is the PI3K enzyme that produces the phosphatidylinositol 3-phospate (PI3P) and regulates the trafficking of proteins and vesicles (Figure 2) [60]. Conversely, the lipid species and membrane modelling involved in phagophore composition, shape, and size are still unclear [61]. In higher eukaryotes, phagophore nucleation occurs on a preexisting membrane [62-64].

\subsection{Autophagosome Formation}

The mechanism involved in tethering and fusion of incoming membranes to phagophore seems to be regulated by PI3K and the Unc-51-like autophagy activating kinase (ULK). These enzymes contribute to the formation and stabilization of phagophore curvature, through the production of PI3P [65]. In this phase, ATG and microtubule-associated proteins 1A/1B light chain 3B (LC3) regulate the double membrane generation. LC3 is a central protein in autophagy and crucial for autophagosome biogenesis, hence LC3 is also used as a marker of autophagosome formation. During autophagosome formation, LC3 is hydrolyzed by ATG proteins and binds phosphatidylethanolamine [66]. This conjugated compound called LC3-II is believed to be involved in the expansion of autophagosome membrane and to be necessary for the fusion events taking place thereafter $[67,68]$.

\subsection{Lysosome Fusion}

After complete fusion of the expanding ends of the phagophore and generation of the autophagosome, the next step consists of the fusion of the autophagosome with the lysosome to form the "autolysosome" (Figure 2) [69]. Fusion of the two organelles is mediated by the small $\mathrm{G}$ protein Rab7 and cellular cytoskeleton; indeed, the administration of nocodazole, which destroys the microtubule structure, blocks autophagosome-lysosome fusion [70]. Cloroquine, an FDA-approved antimalaric drug, blocks autophagic flux by preventing lysosome fusion with the autophagosome [71] and is currently being tested in clinical trials aimed at sensitizing tumors to chemotherapeutics through autophagy inhibition. 
To some extent, autophagy can therefore be exploited to enhance treatment efficacy of MDR cancer cells. This is a narrow path, because we need to keep in mind that autophagy can also contribute to MDR development by accelerating drug degradation during chemotherapy. It is unclear whether autophagy also influences ATP-dependent drug efflux by ABC transporter proteins. Recent studies have shown that expression levels of ABCB1, considered part of the MRP network, and autophagic markers LC3, Beclin1, and Rictor are positively correlated, suggesting a possible connection between autophagy and the $A B C$ transporter system [72]. In keeping with this hypothesis, tumor patients with poor prognosis exhibited a concomitant increase in levels of autophagy and related markers and ATP-dependent drug efflux, possibly synergizing to the development of a robust MDR phenotype [73-75].

Autophagy is relevant in cancer and, in this context, it is thought to play a dual role. On the one hand, it has been shown to prevent cancer development; on the other, once cancer is established, an increase in autophagic flux enables tumor cells to thrive, expand, and resist chemotherapy $[45,56]$. Indeed, autophagy can be also considered a mechanism that protects tumor cells from chemotherapy and facilitates MDR development [76]. Inhibition of autophagy hampers the active elimination of drugs and can, in principle, re-sensitize resistant cancer cells and enhance the efficacy of chemotherapeutic agents. Thus, depending on metabolic or therapeutic stimuli, the modulation of autophagy has either pro-death or pro-survival effects.

The relationship between tumor cell survival and autophagy can only, in part, be explained by the role of autophagy in protecting cells from apoptosis [56,77]. Autophagy does not always spare tumor cells from apoptosis nor is it beneficial for cells at all times. For example, excessive autophagy, a phenomenon characterized by the disproportionate elimination of organelles, leads cancer cells to "autophagic cell death" [78]. Furthermore, autophagy can promote but also inhibit apoptosis in the same tumor cell population in response to various stimuli, such as the death receptor agonists CD95 ligand (CD95L) and tumor necrosis factor-related apoptosis-inducing ligand (TRAIL) [79]. The latter autophagic pathways can be envisioned as targets of antimelanoma therapy for future drugs.

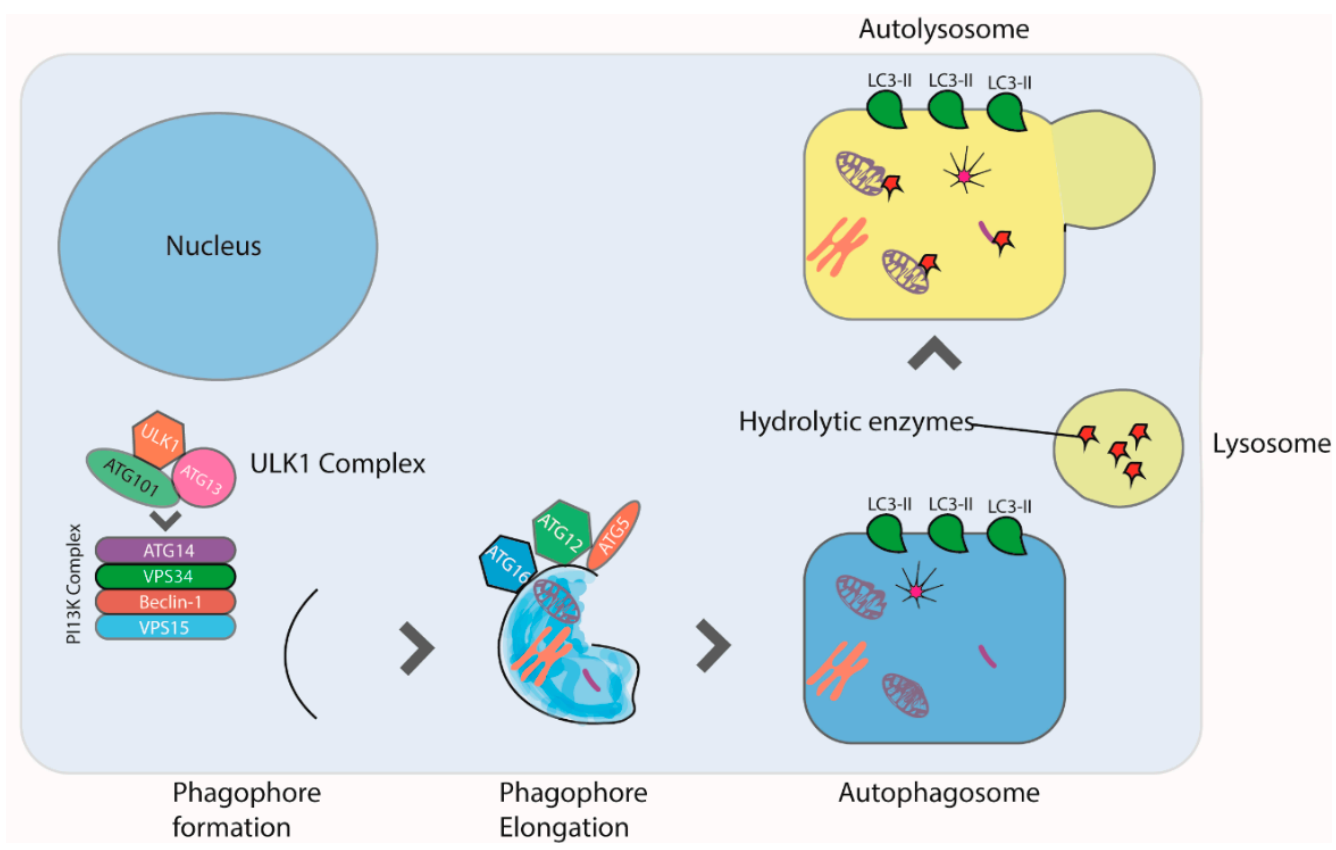

Figure 2. Autophagy is induced in response to starvation, reactive oxygen species, hypoxia, infection, and drugs. Autophagy begins with the formation of the phagophore, a step mediated by the ULK1 complex. Next, phagophore nucleation requires the PI3K complex, which consists of ATG14L, VPS34, Beclin-1, and VPS15 proteins. Autophagosome formation requires the lipidation of LC3 to form LC3II. Finally, the autophagosome fuses with a lysosome forming the autophagolysosome, leading to the degradation of the sequestered organelles and cytosolic proteins. 


\section{Ceramides, Sphingolipids, and Autophagy}

As mentioned, ceramides are at the crossroads between protective and lethal autophagy (Figure 3). In protective autophagy, ceramides may inhibit AKT protein kinase by activating pyrophosphatase protein 2A (PP2A); AKT interferes with the mammalian target of rapamycin (mTOR) kinase pathway, the main negative regulator of autophagy [80]. In other circumstances, ceramides can induce stress to the endoplasmic reticulum (ER), resulting in activation of the ER stress sensor inositol-requiring element 1 (IRE-1). Activation of this stress pathway leads to apoptosis within a certain time span [81]. Ceramides can also induce lethal autophagy, an irreversible process called type II cell death. In this case, they induce the activation of phosphatase-associated proteins (CAPP) that inhibit mTOR [82]. Finally, ceramides are also involved in the increase of autophagic protein Beclin- 1 through activation of the transcription factor c-Jun. It is still unclear how ceramides might play this dual regulation of autophagic flux, but the induction of lethal autophagy may depend on the existence of cellular microdomains where ceramides localize to activate different biological roles.

Ceramides are hydrolyzed to sphingosine by ceramidases. Sphingosine is then converted to S1P by sphingosine kinase-1 (SPHK1) or sphingosine kinase-2 (SPHK2). S1P also regulates autophagy but, unlike ceramides, induces a protective autophagic process [83]. Given the opposite effects of ceramides and sphingosine on autophagy, AC, an enzyme playing a key role in the conversion of ceramides into sphingosine, is pivotal in cell activity and fate.

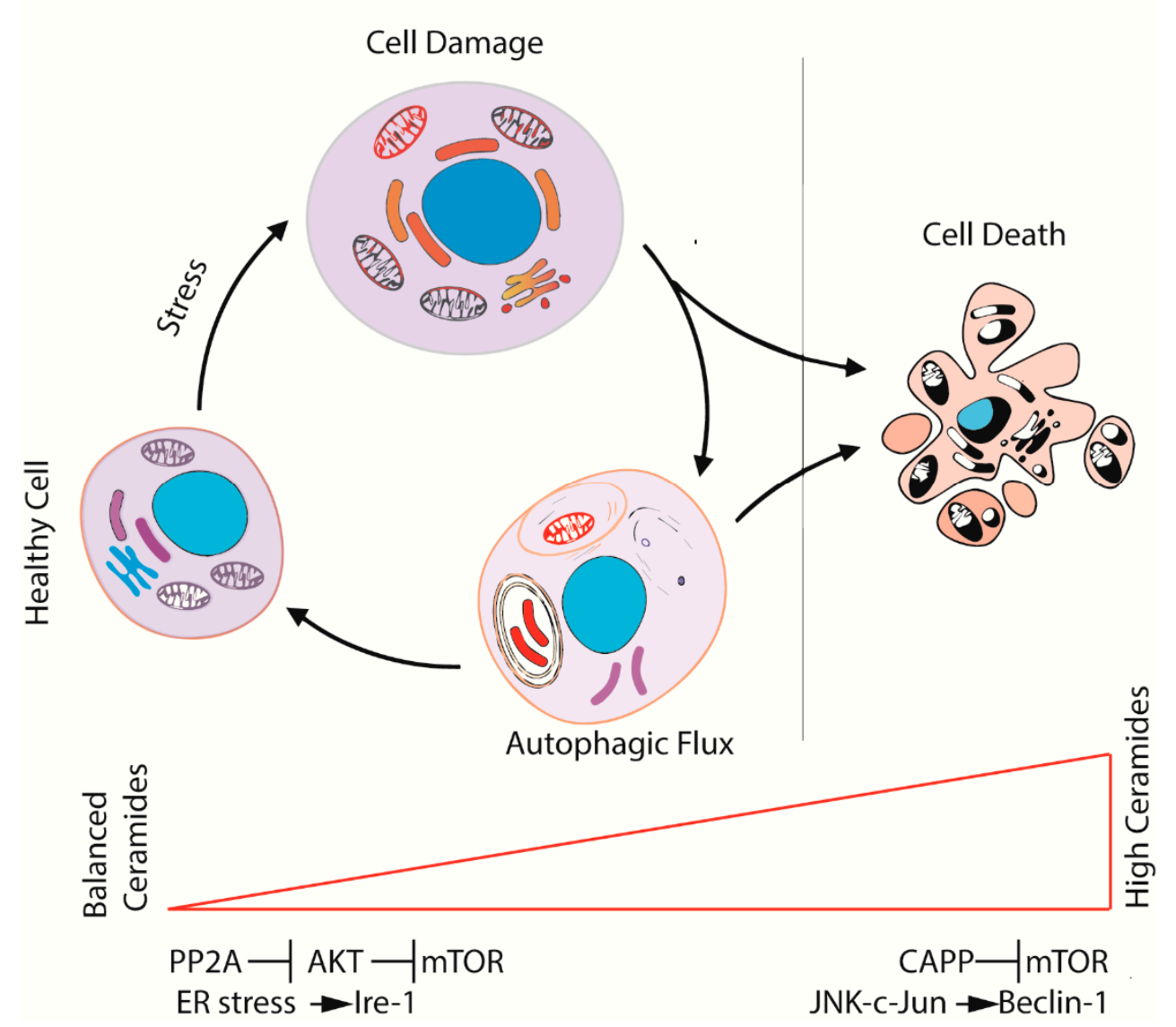

Figure 3. The ceramide-sphingolipid axis contributes to regulate the fate of cells during autophagy. Balanced levels of ceramides activate autophagy through the inhibition of AKT and, consequently, of mTOR (protective autophagy). While the levels of ceramides increase, the over-activation of autophagy leads the cell to autophagic cell death through JNK-c-Jun and Beclin1 signaling. 


\section{The Acid Ceramidase Enzyme}

At least five different human ceramidases have been recognized. These are encoded by distinct genes, which are classified according to their optimal $\mathrm{pH}$ for enzymatic activity: AC (N-acylsphingosine deacylase), alkaline ceramidase, further divided into three isoforms, and neutral ceramidase. AC was identified by Gatt in 1963 and is encoded by ASAH1 that maps to chromosome 8 (p21.3-22). AC is initially translated as a precursor of $53-55 \mathrm{kDa}$ that is then cleaved in the subunits $\alpha(13 \mathrm{kDA})$ and $\beta$ $(40 \mathrm{kDa}) . \mathrm{AC}$ is a lysosomal hydrolase that catalyzes the hydrolysis of ceramide into sphingosine and free fatty acids [84]. Ceramides with an acyl chain of 6 to 16 carbons are the preferential AC substrates [85]. AC deficiency causes Farber disease, a rare lysosomal disease characterized by deformation of the joints, subcutaneous nodules, and progressive hoarseness. It is an autosomal recessive disorder further distinguished into seven subtypes depending on severity and tissues involved. Seventeen different mutations of ASAH1 have been identified in patients with Farber disease. Most of these are single nucleotide substitutions, but small deletions and missense mutations generating a truncated protein have also been found. Farber disease has no cure. In 2002, a AC knockout mouse model of the disease was created, but unexpectedly, the homozygous animals died at an embryonic stage, suggesting that AC also plays an important role during development, at least in mice [81]. In such a knockout model, developing embryos died of apoptosis, possibly due to increased levels of ceramides [86].

Several studies have shown that AC is overexpressed in many tumors [15,87-90]. Concerning melanoma, Realini and coworkers have shown that AC is expressed at higher levels in proliferative melanoma cell lines compared to skin cells, such as keratinocytes, fibroblasts, and melanocytes [33]. In addition, the expression of ASAH1 is greater in proliferative than invasive melanomas. In addition, the prostate tumor cell line DU154, which also overexpresses AC, shows greater proliferation even in the absence of nutrients and increased in vivo tumorigenicity and cell migration compared to other tumor cells exhibiting normal AC levels [91,92]. Resistance to starvation may be due to the activation of protective autophagy, suggesting that AC can influence the response to chemotherapeutics not only by affecting apoptosis. In a paper published in 2011, Turner and colleagues showed that also prostate cancer tumor lines overexpressing AC have high autophagic activity. These tumor lines show resistance to conditions of nutrient deprivation and exhibit high expression of the LC3-II protein. From these results, the authors concluded that autophagy contributes to creating an "insult-ready" phenotype and AC overexpression makes these cells more resistant to stress [93].

The observation that AC is overexpressed in pediatric brain tumor lines resistant to chemoand radiotherapy [94] led to the development and testing of carmofur, a potent AC inhibitor and chemotherapeutic agent in these neoplastic cells. Following treatment, the tumor cells accumulated high levels of ceramides and died off [95-99].

Studies on glioblastoma cells have shown that gamma radiation increases AC activity in these cells [100]. In addition, treatment of these tumor cells with an inhibitor of AC, N-oleylethanolamine (NOE), increases ceramide production and apoptosis in response to gamma radiation, suggesting that AC exerts a protective role during radiotherapy by reducing ceramides. Treatment with daunorubicin (DNR) was also shown to induce overexpression of AC in hepatocellular lines [101]. To investigate this phenomenon, the authors knocked down AC or added exogenous S1P to these tumor cells and discovered that the ablation of AC increased sensitivity to DNR through the induction of apoptosis; in contrast, SP1 addition promoted tumor cell survival by the inhibition of apoptosis [102]. The mechanism through which AC overexpression favors tumor survival has not yet been clarified. It is possible that cells resist better to various stress stimuli in the presence of low levels of ceramides and/or high levels of S1P produced by the AC-catalyzed hydrolysis of ceramides.

We have previously shown that ceramide metabolism and AC control melanoma progression [14]. This finding rendered AC an important therapeutic target and, as a result, several pharmacological inhibitors and gene silencing systems have been developed to evaluate the importance of AC in tumor development. Over the years, in addition to NOE, other ceramide-like compounds have been developed to inhibit AC activity, for example, (1S, 2R) -D-erythro-2 (N-myristoylamino) -1- phenyl 1 - 
propanol (De-MAPP) and its B13 analog, which potently inhibit AC in vitro in human melanoma cell lines. Unfortunately, these inhibitors have modest efficacy in vivo.

Bedia and collaborators (2011) used dacarbazine, an imidazole carboxamide commonly used in the treatment of metastatic melanoma and with low efficacy against the invasive melanoma cell line A375 [59]. This study evidenced that sensitivity to the drug depended on the levels of AC expression. A few years ago, Realini and collaborators showed that carmofur, a chemotherapeutic agent used in Japan since 1981 against colorectal cancer, is a potent AC inhibitor in A375 melanoma cell line [103]. Treatment of this cell line with dacarbazine led to significant loss of AC activity, increment of C16 and C18 ceramidase, and concomitant restoration of sensitivity to currently used melanoma drugs [49]. Encouraged by these studies, Realini and collaborators developed the carmofur derivative ARN 14988 inhibiting AC activity in a time/dose-dependent manner in both invasive and proliferative melanoma cell lines. Compared to carmofur, ARN14988 lacks 5-Fluoro-uridine, has lower cytotoxic effects per se but enhances synergistically the cytotoxic effect of standard chemotherapeutics. In the proliferative melanoma line G361, for instance, ARN 14988 acted in a synergistic way with 5-Fluorouracil, Taxol and vemurafenib [104]. For these features, ARN 14988 is reputed more suitable as an adjuvant rather than a bona fide antineoplastic drug.

Derangement of the ceramide-sphingolipid pathway also alters cell cycle. Only $4 \%$ of the above-mentioned A375 cells knocked out of ASAH1 (A375 ASAH1-null cells) entered phase G2, compared to $25 \%$ of controls, and about $50 \%$ of ASAH1-null cells remained in phase G1 or in phase $\mathrm{S}(46 \%)$ [14]. For this reason, the interaction of ceramides with the cell cycle cascade is thought to occur through CDK inhibitor p27, which controls the transition from G1-S to G2-mitosis phase [105]. $\mathrm{AC}$ ablation altered not only the levels but also the type of ceramides, with an increase in long-chain molecules such as C14:0, C16:0, and C18:0. Furthermore, a higher percentage of ASAH1-null cells underwent apoptosis compared to wild-type cells [14]. Taken together, in vitro findings support the idea that AC overexpression favors resistance to chemotherapeutic treatment by decreasing the levels of ceramides, which, in turn, lead to cell death. As an additional effect, the imbalance of ceramide-sphingolipid levels, involved in the autophagic process and embedding pro-apoptotic (ceramides) or anti-apoptotic (sphingosine and S1P derivative) signals, helps cancer cells to withstand stress. This makes AC a potential target to develop either chemotherapeutic agents or adjuvant molecules that make tumor cells less prone to survive in the face of antitumor treatment.

\section{Conclusions}

Autophagy is coming out as a process that dictates opposite fates for cells: it can protect cells from apoptotic stimuli (protective autophagy) or drive cells to death (lethal autophagy), as illustrated in Figure 4. AC has been shown to participate in determining one outcome or the other as it regulates levels of molecules possessing pro- or anti-apoptotic effects. A future challenge might definitely be shedding light on what drives the cell into one or the other possible direction.

Tumors expressing high levels of AC and consequently lower ceramide levels show higher protection from stress stimuli, including chemotherapy. It is worth mentioning, however, that localization of AC in cancer cells is not limited to lysosomes, like in normal cells, but is also present in the cytoplasm [33]. Although the role and activity of cytoplasmic AC are still unclear, it is arguable that the adjuvant effect showed by some AC inhibitors depends on the different localization of the enzyme rather than its sole inhibition in tumor cells. An innovative approach to avoid and circumvent MDR is, therefore, the co-delivery of AC inhibitors and chemotherapeutic agents, aimed at disarming the complex apparatus at the disposal of cancer cells to blunt drug efficacy. 


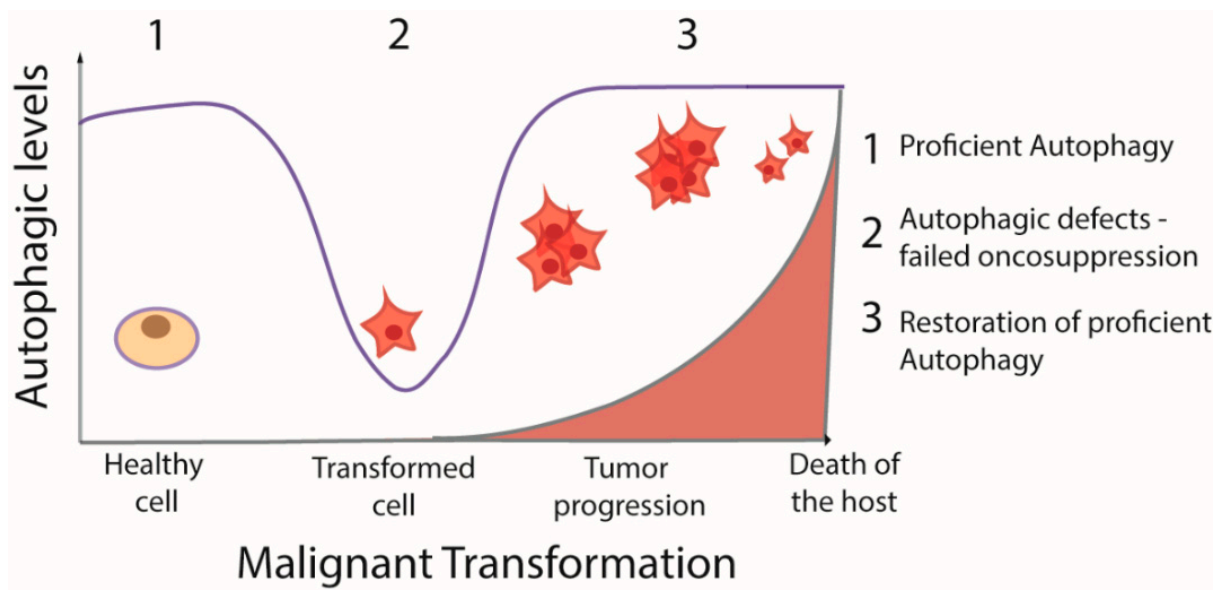

Figure 4. Schematic model of the role of autophagy during cancer progression. Proficient autophagy is blocked during cell transformation and restored in the advanced phases of tumor progression.

Author Contributions: Conceptualization, M.L. and M.P.; Funding acquisition, M.P.; Writing-original draft preparation and drawing of figures, M.L., R.A. and V.L.R.; Visualization, M.L. and V.L.R.; Writing一review and editing, M.L., G.F., and M.P.

Funding: This work was supported by Progetto di Ricerca di Ateneo 2017-2018 of the University of Pisa, Project No. PRA_2017_38, DR n. 83/2017, and by Bando Prin 2017, Progetto di Ricerca di Interesse Nazionale, Project No. 2017KM79NN Decreto n. 512, 20.03.2019.

Conflicts of Interest: The authors declare no conflict of interest.

\section{References}

1. Juhl, A.L.; Byers, T.E.; Robinson, W.A.; Robinson, W.A.; Morelli, J.G.; Crane, L.A. The anatomic distribution of melanoma and relationships with childhood nevus distribution in Colorado. Melanoma Res. 2009, 19, 252-259. [CrossRef] [PubMed]

2. Gibbs, D.C.; Orlow, I.; Kanetsky, P.A.; Luo, L.; Kricker, A.; Armstrong, B.K.; Anton-Culver, H.; Gruber, S.B.; Marrett, L.D.; Gallagher, R.P.; et al. Inherited genetic variants associated with occurrence of multiple primary melanoma. Cancer Epidemiol. Biomarkers Prev. 2015, 24, 992-997. [CrossRef] [PubMed]

3. MacKie, R.M.; Hauschild, A.; Eggermont, A.M. Epidemiology of invasive cutaneous melanoma. Ann. Oncol. 2009, 20 (Suppl. 6), vi1-vi7. [CrossRef]

4. Wellbrock, C.; Karasarides, M.; Marais, R. The RAF proteins take centre stage. Nat. Rev. Mol. Cell Biol. 2004, 5, 875-885. [CrossRef] [PubMed]

5. Davies, H.; Bignell, G.R.; Cox, C.; Edkins, S.; Clegg, S.; Teague, J.; Woffendin, H.; Garnett, M.J.; Bottomley, W.; Davis, N.; et al. Mutations of the BRAF gene in human cancer. Nature 2002, 417, 949-954. [CrossRef] [PubMed]

6. Gray-Schopfer, V.C.; da Rocha Dias, S.; Marais, R. The role of B-RAF in melanoma. Cancer Metastasis Rev. 2005, 24, 165-183. [CrossRef] [PubMed]

7. Luke, J.J.; Flaherty, K.T.; Ribas, A.; Long, G.V. Targeted agents and immunotherapies: Optimizing outcomes in melanoma. Nat. Rev. Clin. Oncol. 2017, 14, 463-482. [CrossRef] [PubMed]

8. Morrison, D.K. MAP kinase pathways. Cold Spring Harb Perspect. Biol. 2012, 4. [CrossRef] [PubMed]

9. Zhang, W.; Liu, H.T. MAPK signal pathways in the regulation of cell proliferation in mammalian cells. Cell Res. 2002, 12, 9-18. [CrossRef] [PubMed]

10. Matsuda, H.; Hirata, N.; Kawaguchi, Y.; Naruto, S.; Takata, T.; Oyama, M.; Iinuma, M.; Kubo, M. Melanogenesis stimulation in murine B16 melanoma cells by Kava (Piper methysticum) rhizome extract and kavalactones. Biol. Pharm. Bull. 2006, 29, 834-837. [CrossRef]

11. Levy, C.; Khaled, M.; Fisher, D.E. MITF: Master regulator of melanocyte development and melanoma oncogene. Trends Mol. Med. 2006, 12, 406-414. [CrossRef] [PubMed] 
12. Levy, C.; Lee, Y.N.; Nechushtan, H.; Schueler-Furman, O.; Sonnenblick, A.; Hacohen, S.; Razin, E. Identifying a common molecular mechanism for inhibition of MITF and STAT3 by PIAS3. Blood 2006, 107, 2839-2845. [CrossRef] [PubMed]

13. Aprelikova, O.; Xiong, Y.; Liu, E.T. Both p16 and p21 families of cyclin-dependent kinase (CDK) inhibitors block the phosphorylation of cyclin-dependent kinases by the CDK-activating kinase. J. Biol. Chem. 1995, 270, 18195-18197. [CrossRef] [PubMed]

14. Lai, M.; Realini, N.; La Ferla, M.; Passalacqua, I.; Matteoli, G.; Ganesan, A.; Pistello, M.; Mazzanti, C.M.; Piomelli, D. Complete Acid Ceramidase ablation prevents cancer-initiating cell formation in melanoma cells. Sci. Rep. 2017, 7, 7411. [CrossRef] [PubMed]

15. Leclerc, J.; Garandeau, D.; Pandiani, C.; Gaudel, C.; Bille, K.; Nottet, N.; Garcia, V.; Colosetti, P.; Pagnotta, S.; Bahadoran, P.; et al. Lysosomal acid ceramidase ASAH1 controls the transition between invasive and proliferative phenotype in melanoma cells. Oncogene 2019, 38, 1282-1295. [CrossRef] [PubMed]

16. Zhang, L.Y.; Ho-Fun Lee, V.; Wong, A.M.; Kwong, D.L.; Zhu, Y.H.; Dong, S.S.; Kong, K.L.; Chen, J.; Tsao, S.W.; Guan, X.Y.; et al. MicroRNA-144 promotes cell proliferation, migration and invasion in nasopharyngeal carcinoma through repression of PTEN. Carcinogenesis 2013, 34, 454-463. [CrossRef] [PubMed]

17. Stahl, J.M.; Cheung, M.; Sharma, A.; Trivedi, N.R.; Shanmugam, S.; Robertson, G.P. Loss of PTEN promotes umor development in malignant melanoma. Cancer Res. 2003, 63, 2881-2890.

18. Birck, A.; Ahrenkiel, V.; Zeuthen, J.; Hou-Jensen, K.; Guldberg, P. Mutation and allelic loss of the PTEN/MMAC1 gene in primary and metastatic melanoma biopsies. J. Investig. Dermatol. 2000, 114, 277-280. [CrossRef] [PubMed]

19. de Snoo, F.A.; Hayward, N.K. Cutaneous melanoma susceptibility and progression genes. Cancer Lett. 2005, 230, 153-186. [CrossRef]

20. Meyle, K.D.; Guldberg, P. Genetic risk factors for melanoma. Hum. Genet. 2009, 126, 499-510. [CrossRef]

21. Dankort, D.; Curley, D.P.; Cartlidge, R.A.; Nelson, B.; Karnezis, A.N.; Damsky, W.E., Jr.; You, M.J.; DePinho, R.A.; McMahon, M.; Bosenberg, M. Braf(V600E) cooperates with Pten loss to induce metastatic melanoma. Nat. Genet. 2009, 41, 544-552. [CrossRef] [PubMed]

22. Diaz-Flores, E.; Shannon, K. Targeting oncogenic Ras. Genes Dev. 2007, 21, 1989-1992. [CrossRef] [PubMed]

23. Johnson, D.B.; Childress, M.A.; Chalmers, Z.R.; Johnson, D.B.; Childress, M.A.; Chalmers, Z.R.; Frampton, G.M.; Ali, S.M.; Rubinstein, S.M.; Fabrizio, D.; et al. BRAF internal deletions and resistance to BRAF/MEK inhibitor therapy. Pigment Cell Melanoma Res. 2018, 31, 432-436. [CrossRef] [PubMed]

24. Colone, M.; Calcabrini, A.; Toccacieli, L.; Bozzuto, G.; Stringaro, A.; Gentile, M.; Cianfriglia, M.; Ciervo, A.; Caraglia, M.; Budillon, A.; et al. The multidrug transporter P-glycoprotein: A mediator of melanoma invasion? J. Investig. Dermatol. 2008, 128, 957-971. [CrossRef] [PubMed]

25. Molinari, A.; Toccacieli, L.; Calcabrini, A.; Diociaiuti, M.; Cianfriglia, M.; Arancia, G. Induction of P-glycoprotein expression on the plasma membrane of human melanoma cells. Anticancer Res. 2000, 20, 2691-2696. [PubMed]

26. Walsh, N.; Kennedy, S.; Larkin, A.M.; Tryfonopoulos, D.; Eustace, A.J.; Mahgoub, T.; Conway, C.; Oglesby, I.; Collins, D.; Ballot, J.; et al. Membrane transport proteins in human melanoma: Associations with tumour aggressiveness and metastasis. Br. J. Cancer 2010, 102, 1157-1162. [CrossRef] [PubMed]

27. Elliott, A.M.; Al-Hajj, M.A. ABCB8 mediates doxorubicin resistance in melanoma cells by protecting the mitochondrial genome. Mol. Cancer Res. 2009, 7, 79-87. [CrossRef] [PubMed]

28. Annereau, J.P.; Szakacs, G.; Tucker, C.J.; Arciello, A.; Cardarelli, C.; Collins, J.; Grissom, S.; Zeeberg, B.R.; Reinhold, W.; Weinstein, J.N.; et al. Analysis of ATP-binding cassette transporter expression in drug-selected cell lines by a microarray dedicated to multidrug resistance. Mol. Pharmacol. 2004, 66, 1397-1405. [CrossRef] [PubMed]

29. Erb, P.; Ji, J.; Kump, E.; Mielgo, A.; Wernli, M. Apoptosis and pathogenesis of melanoma and nonmelanoma skin cancer. Adv. Exp. Med. Biol. 2008, 624, 283-295.

30. Fritsche, M.K.; Knopf, A. The Tumor Suppressor p53 in Mucosal Melanoma of the Head and Neck. Genes (Basel) 2017, 8, 384. [CrossRef] [PubMed]

31. Ouyang, Q.; Duan, Z.; Jiao, G.; Lei, J. A Biomimic Reconstituted High-Density-Lipoprotein-Based Drug and p53 Gene Co-delivery System for Effective Antiangiogenesis Therapy of Bladder Cancer. Nanoscale Res. Lett. 2015, 10, 965. [CrossRef] [PubMed] 
32. Blandino, G.; Di Agostino, S. New therapeutic strategies to treat human cancers expressing mutant p53 proteins. J. Exp. Clin. Cancer Res. 2018, 37, 30. [CrossRef] [PubMed]

33. Realini, N.; Palese, F.; Pizzirani, D.; Pontis, S.; Basit, A.; Bach, A.; Ganesan, A.; Piomelli, D. Acid Ceramidase in Melanoma: Expression, localization, and effects of pharmacological inhibition. J. Biol. Chem. 2016, 291, 2422-2434. [CrossRef] [PubMed]

34. Hannun, Y.A.; Obeid, L.M. Many ceramides. J. Biol. Chem. 2011, 286, 27855-27862. [CrossRef] [PubMed]

35. Trayssac, M.; Hannun, Y.A.; Obeid, L.M. Role of sphingolipids in senescence: Implication in aging and age-related diseases. J. Clin. Investig. 2018, 128, 2702-2712. [CrossRef] [PubMed]

36. Hannun, Y.A.; Obeid, L.M. Sphingolipids and their metabolism in physiology and disease. Nat. Rev. Mol. Cell Biol. 2018, 19, 175-191. [CrossRef] [PubMed]

37. Garcia-Barros, M.; Coant, N.; Truman, J.P.; Wada, M.; Snider, A.J.; Truman, J.P.; Wu, B.X.; Furuya, H.; Clarke, C.J.; Bialkowska, A.B.; et al. Sphingolipids in colon cancer. Biochim. Biophys. Acta 2014, 1841, 773-782.

38. Di Bartolomeo, S.; Di Sano, F.; Piacentini, M.; Spinedi, A. Apoptosis induced by doxorubicin in neurotumor cells is divorced from drug effects on ceramide accumulation and may involve cell cycle-dependent caspase activation. J. Neurochem. 2000, 75, 532-539. [CrossRef]

39. Chen, L.; Alrbyawi, H.; Poudel, I.; Arnold, R.D.; Babu, R.J. Co-delivery of Doxorubicin and Ceramide in a Liposomal Formulation Enhances Cytotoxicity in Murine B16BL6 Melanoma Cell Lines. AAPS PharmSciTech 2019, 20, 99. [CrossRef]

40. Su, X.; Song, H.; Niu, F.; Yang, K.; Kou, G.; Wang, H.; Chen, X.; Li, W.; Guo, S.; Li, J.; et al. Co-delivery of doxorubicin and PEGylated C16-ceramide by nanoliposomes for enhanced therapy against multidrug resistance. Nanomedicine (Lond) 2015, 10, 2033-2050. [CrossRef]

41. Luo, X.; Cheng, C.; Tan, Z.; Li, N.; Tang, M.; Yang, L.; Cao, Y. Emerging roles of lipid metabolism in cancer metastasis. Mol. Cancer 2017, 16, 76. [CrossRef] [PubMed]

42. Weiss, M.; Hettmer, S.; Smith, P.; Ladisch, S. Inhibition of melanoma tumor growth by a novel inhibitor of glucosylceramide synthase. Cancer Res. 2003, 63, 3654-3658. [PubMed]

43. Deng, W.; Li, R.; Guerrera, M.; Liu, Y.; Ladisch, S. Transfection of glucosylceramide synthase antisense inhibits mouse melanoma formation. Glycobiology 2002, 12, 145-152. [CrossRef] [PubMed]

44. Gouaze, V.; Liu, Y.Y.; Prickett, C.S.; Prickett, C.S.; Yu, J.Y.; Giuliano, A.E.; Cabot, M.C. Glucosylceramide synthase blockade down-regulates P-glycoprotein and resensitizes multidrug-resistant breast cancer cells to anticancer drugs. Cancer Res. 2005, 65, 3861-3867. [CrossRef] [PubMed]

45. Veldman, R.J.; Mita, A.; Cuvillier, O.; Garcia, V.; Klappe, K.; Medin, J.A.; Campbell, J.D.; Carpentier, S.; Kok, J.W.; Levade, T. The absence of functional glucosylceramide synthase does not sensitize melanoma cells for anticancer drugs. FASEB J. 2003, 17, 1144-1146. [CrossRef] [PubMed]

46. LaMontagne, K.; Littlewood-Evans, A.; Schnell, C.; Schnell, C.; O’Reilly, T.; Wyder, L.; Sanchez, T.; Probst, B.; Butler, J.; Wood, A.; et al. Antagonism of sphingosine-1-phosphate receptors by FTY720 inhibits angiogenesis and tumor vascularization. Cancer Res. 2006, 66, 221-231. [CrossRef]

47. Pyne, N.J.; Pyne, S. Sphingosine 1-phosphate and cancer. Nat. Rev. Cancer 2010, 10, 489-503. [CrossRef]

48. Garandeau, D.; Noujarede, J.; Leclerc, J.; Imbert, C.; Garcia, V.; Bats, M.L.; Rambow, F.; Gilhodes, J.; Filleron, T.; Meyer, N.; et al. Targeting the Sphingosine 1-Phosphate Axis Exerts Potent Antitumor Activity in BRAFi-Resistant Melanomas. Mol. Cancer Ther. 2019, 18, 289-300. [CrossRef]

49. Bedia, C.; Casas, J.; Andrieu-Abadie, N.; Fabriàs, G.; Levade, T. Acid ceramidase expression modulates the sensitivity of A375 melanoma cells to dacarbazine. J. Biol. Chem. 2011, 286, 28200-28209. [CrossRef]

50. Ortega, J.A.; Arencibia, J.M.; La Sala, G.; Borgogno, M.; Bauer, I.; Bono, L.; Braccia, C.; Armirotti, A.; Girotto, S.; Ganesan, A.; et al. Pharmacophore Identification and Scaffold Exploration to Discover Novel, Potent, and Chemically Stable Inhibitors of Acid Ceramidase in Melanoma Cells. J. Med. Chem. 2017, 60, 5800-5815. [CrossRef]

51. Hannun, Y.A.; Obeid, L.M. Principles of bioactive lipid signalling: Lessons from sphingolipids. Nat. Rev. Mol. Cell Biol. 2008, 9, 139-150. [CrossRef] [PubMed]

52. Pyne, N.J.; El Buri, A.; Adams, D.R.; Pyne, S. Sphingosine 1-phosphate and cancer. Adv. Biol. Regul. 2018, 68, 97-106. [CrossRef] [PubMed]

53. Ogretmen, B. Sphingolipid metabolism in cancer signalling and therapy. Nat. Rev. Cancer 2018, 18, 33-50. [CrossRef] [PubMed] 
54. Mistry, P.K.; Taddei, T.; vom Dahl, S.; Rosenbloom, B.E. Gaucher disease and malignancy: A model for cancer pathogenesis in an inborn error of metabolism. Crit. Rev. Oncog. 2013, 18, 235-246. [CrossRef] [PubMed]

55. Rosenbloom, B.E.; Weinreb, N.J.; Zimran, A.; Kacena, K.A.; Charrow, J.; Ward, E. Gaucher disease and cancer incidence: A study from the Gaucher Registry. Blood 2005, 105, 4569-4572. [CrossRef] [PubMed]

56. Amaravadi, R.; Kimmelman, A.C.; White, E. Recent insights into the function of autophagy in cancer. Genes Dev. 2016, 30, 1913-1930. [CrossRef] [PubMed]

57. Young, M.M.; Wang, H.G. Sphingolipids as Regulators of Autophagy and Endocytic Trafficking. Adv. Cancer Res. 2018, 140, 27-60. [PubMed]

58. Young, M.M.; Kester, M.; Wang, H.G. Sphingolipids: Regulators of crosstalk between apoptosis and autophagy. J. Lipid Res. 2013, 54, 5-19. [CrossRef] [PubMed]

59. Bedia, C.; Levade, T.; Codogno, P. Regulation of autophagy by sphingolipids. Anticancer Agents Med. Chem. 2011, 11, 844-853. [CrossRef]

60. Nascimbeni, A.C.; Codogno, P.; Morel, E. Phosphatidylinositol-3-phosphate in the regulation of autophagy membrane dynamics. FEBS J. 2017, 284, 1267-1278. [CrossRef]

61. Tooze, S.A.; Abada, A.; Elazar, Z. Endocytosis and autophagy: Exploitation or cooperation? Cold Spring Harb Perspect. Biol. 2014, 6, a018358. [CrossRef] [PubMed]

62. Maejima, I.; Takahashi, A.; Omori, H.; Kimura, T.; Takabatake, Y.; Saitoh, T.; Yamamoto, A.; Hamasaki, M.; Noda, T.; Isaka, Y.; et al. Autophagy sequesters damaged lysosomes to control lysosomal biogenesis and kidney injury. EMBO J. 2013, 32, 2336-2347. [CrossRef] [PubMed]

63. Shibutani, S.T.; Yoshimori, T. A current perspective of autophagosome biogenesis. Cell Res. 2014, $24,58-68$. [CrossRef] [PubMed]

64. Osawa, T.; Kotani, T.; Kawaoka, T.; Hirata, E.; Suzuki, K.; Nakatogawa, H.; Ohsumi, Y.; Noda, N.N. Atg2 mediates direct lipid transfer between membranes for autophagosome formation. Nat. Struct. Mol. Biol. 2019, 26, 281-288. [CrossRef] [PubMed]

65. Gimenez-Xavier, P.; Francisco, R.; Platini, F.; Pérez, R.; Ambrosio, S. LC3-I conversion to LC3-II does not necessarily result in complete autophagy. Int. J. Mol. Med. 2008, 22, 781-785. [PubMed]

66. Bissa, B.; Deretic, V. Autophagosome Formation: Cutting the Gordian Knot at the ER. Curr. Biol. 2018, 28, R347-R349. [CrossRef] [PubMed]

67. Deter, R.L.; De Duve, C. Influence of glucagon, an inducer of cellular autophagy, on some physical properties of rat liver lysosomes. J. Cell Biol. 1967, 33, 437-449. [CrossRef]

68. Webb, J.L.; Ravikumar, B.; Rubinsztein, D.C. Microtubule disruption inhibits autophagosome-lysosome fusion: Implications for studying the roles of aggresomes in polyglutamine diseases. Int. J. Biochem. Cell Biol. 2004, 36, 2541-2550. [CrossRef]

69. Mauthe, M.; Orhon, I.; Rocchi, C.; Zhou, X.; Luhr, M.; Hijlkema, K.J.; Coppes, R.P.; Engedal, N.; Mari, M.; Reggiori, F. Chloroquine inhibits autophagic flux by decreasing autophagosome-lysosome fusion. Autophagy 2018, 14, 1435-1455. [CrossRef]

70. Naik, P.P.; Mukhopadhyay, S.; Panda, P.K.; Sinha, N.; Das, C.K.; Mishra, R.; Patil, S.; Bhutia, S.K. Autophagy regulates cisplatin-induced stemness and chemoresistance via the upregulation of CD44, ABCB1 and ADAM17 in oral squamous cell carcinoma. Cell Prolif. 2018, 51. [CrossRef]

71. Terabe, T.; Uchida, F.; Nagai, H.; Nagai, H.; Omori, S.; Ishibashi-Kanno, N.; Hasegawa, S.; Yamagata, K.; Gosho, M.; Yanagawa, T.; et al. Expression of autophagy-related markers at the surgical margin of oral squamous cell carcinoma correlates with poor prognosis and tumor recurrence. Hum. Pathol. 2018, 73, 156-163. [CrossRef] [PubMed]

72. Nitta, T.; Sato, Y.; Ren, X.S.; Harada, K.; Sasaki, M.; Hirano, S.; Nakanuma, Y. Autophagy may promote carcinoma cell invasion and correlate with poor prognosis in cholangiocarcinoma. Int. J. Clin. Exp. Pathol. 2014, 7, 4913-4921. [PubMed]

73. Winardi, D.; Tsai, H.P.; Chai, C.Y.; Chung, C.L.; Loh, J.K.; Chen, Y.H.; Hsieh, C.L. Correlation of altered expression of the autophagy marker LC3B with poor prognosis in astrocytoma. Biomed. Res. Int. 2014, 2014, 723176. [CrossRef] [PubMed]

74. Gibson, S.B. Autophagy in clear cell ovarian cancer, a potential marker for hypoxia and poor prognosis?(\#). J. Pathol. 2012, 228, 434-436. [PubMed] 
75. Ding, Z.B.; Shi, Y.H.; Zhou, J.; Shi, G.M.; Ke, A.W.; Qiu, S.J.; Wang, X.Y.; Dai, Z.; Xu, Y.; Fan, J. Association of autophagy defect with a malignant phenotype and poor prognosis of hepatocellular carcinoma. Cancer Res. 2008, 68, 9167-9175. [CrossRef] [PubMed]

76. Liang, B.; Liu, X.; Liu, Y.; Kong, D.; Liu, X.; Zhong, R.; Ma, S. Inhibition of autophagy sensitizes MDR-phenotype ovarian cancer SKVCR cells to chemotherapy. Biomed. Pharmacother. 2016, 82, 98-105. [CrossRef] [PubMed]

77. Wu, J.C.; Tsai, H.E.; Liu, G.S.; Wu, C.S.; Tai, M.H. Autophagic cell death participates in POMC-induced melanoma suppression. Cell Death Discov. 2018, 4, 11. [CrossRef]

78. Shimizu, S. Autophagic Cell Death and Cancer Chemotherapeutics. In Innovative Medicine: Basic Research and Development; Nakao, K., Minato, N., Uemoto, S., Eds.; Springer: Tokyo, Japan, 2015; pp. 219-226.

79. Gump, J.M.; Staskiewicz, L.; Morgan, M.J.; Bamberg, A.; Riches, D.W.; Thorburn, A. Autophagy variation within a cell population determines cell fate through selective degradation of Fap-1. Nat. Cell Biol. 2014, 16, 47-54. [CrossRef]

80. Jiang, W.; Ogretmen, B. Autophagy paradox and ceramide. Biochim. Biophys. Acta 2014, 1841, $783-792$. [CrossRef]

81. Jiang, W.; Ogretmen, B. Ceramide stress in survival versus lethal autophagy paradox: Ceramide targets autophagosomes to mitochondria and induces lethal mitophagy. Autophagy 2013, 9, 258-259. [CrossRef]

82. Taniguchi, M.; Kitatani, K.; Kondo, T.; Hashimoto-Nishimura, M.; Asano, S.; Hayashi, A.; Mitsutake, S.; Igarashi, Y.; Umehara, H.; Takeya, H.; et al. Regulation of autophagy and its associated cell death by "sphingolipid rheostat": Reciprocal role of ceramide and sphingosine 1-phosphate in the mammalian target of rapamycin pathway. J. Biol. Chem. 2012, 287, 39898-39910. [CrossRef] [PubMed]

83. Yang, W.; Li, Q.; Pan, Z. Sphingosine-1-phosphate promotes extravillous trophoblast cell invasion by activating MEK/ERK/MMP-2 signaling pathways via S1P/S1PR1 axis activation. PLoS ONE 2014, 9, e106725. [CrossRef] [PubMed]

84. Kim, M.K.; Lee, H.Y.; Kwak, J.Y.; Park, J.I.; Yun, J.; Bae, Y.S. Sphingosine-1-phosphate stimulates rat primary chondrocyte proliferation. Biochem. Biophys. Res. Commun. 2006, 345, 67-73. [CrossRef] [PubMed]

85. Mao, C.; Obeid, L.M. Ceramidases: Regulators of cellular responses mediated by ceramide, sphingosine, and sphingosine-1-phosphate. Biochim. Biophys. Acta 2008, 1781, 424-434. [CrossRef] [PubMed]

86. Park, J.H.; Schuchman, E.H. Acid ceramidase and human disease. Biochim. Biophys. Acta 2006, 1758, 2133-2138. [CrossRef] [PubMed]

87. Eliyahu, E.; Park, J.H.; Shtraizent, N.; He, X.; Schuchman, E.H. Acid ceramidase is a novel factor required for early embryo survival. FASEB J. 2007, 21, 1403-1409. [CrossRef]

88. Mahdy, A.E.; Cheng, J.C.; Li, J.; Elojeimy, S.; Meacham, W.D.; Turner, L.S.; Bai, A.; Gault, C.R.; McPherson, A.S.; Garcia, N.; et al. Acid ceramidase upregulation in prostate cancer cells confers resistance to radiation: AC inhibition, a potential radiosensitizer. Mol. Ther. 2009, 17, 430-438. [CrossRef]

89. Tan, S.F.; Dunton, W.; Liu, X.; Fox, T.E.; Morad, S.A.F.; Desai, D.; Doi, K.; Conaway, M.R.; Amin, S.; Claxton, D.F.; et al. Acid ceramidase promotes drug resistance in acute myeloid leukemia through NF-kB-dependent P-glycoprotein upregulation. J. Lipid Res. 2019, 60, 1078-1086. [CrossRef]

90. Klobucar, M.; Grbcic, P.; Pavelic, S.K.; Jonjić, N.; Visentin, S.; Sedić, M. Acid ceramidase inhibition sensitizes human colon cancer cells to oxaliplatin through downregulation of transglutaminase 2 and beta1 integrin/FAK-mediated signalling. Biochem. Biophys. Res. Commun. 2018, 503, 843-848. [CrossRef]

91. Saad, A.F.; Meacham, W.D.; Bai, A.; Anelli, V.; Elojeimy, S.; Mahdy, A.E.; Turner, L.S.; Cheng, J.; Bielawska, A.; Bielawski, J.; et al. The functional effects of acid ceramidase overexpression in prostate cancer progression and resistance to chemotherapy. Cancer Biol. Ther. 2007, 6, 1455-1460. [CrossRef]

92. Elojeimy, S.; Liu, X.; McKillop, J.C.; El-Zawahry, A.M.; Holman, D.H.; Cheng, J.Y.; Meacham, W.D.; Mahdy, A.E.; Saad, A.F.; Turner, L.S.; et al. Role of acid ceramidase in resistance to FasL: Therapeutic approaches based on acid ceramidase inhibitors and FasL gene therapy. Mol. Ther. 2007, 15, 1259-1263. [CrossRef] [PubMed]

93. Turner, L.S.; Cheng, J.C.; Beckham, T.H.; Keane, T.E.; Norris, J.S.; Liu, X. Autophagy is increased in prostate cancer cells overexpressing acid ceramidase and enhances resistance to C6 ceramide. Prostate Cancer Prostatic Dis. 2011, 14, 30-37. [CrossRef] [PubMed] 
94. Pizzirani, D.; Bach, A.; Realini, N.; Armirotti, A.; Mengatto, L.; Bauer, I.; Girotto, S.; Pagliuca, C.; De Vivo, M.; Summa, M.; et al. Benzoxazolone carboxamides: Potent and systemically active inhibitors of intracellular acid ceramidase. Angew. Chem. Int. Ed. Engl. 2015, 54, 485-489. [CrossRef] [PubMed]

95. Dementiev, A.; Joachimiak, A.; Nguyen, H.; Gorelik, A.; Illes, K.; Shabani, S.; Gelsomino, M.; Ahn, E.E.; Nagar, B.; Doan, N. Molecular mechanism of inhibition of acid ceramidase by carmofur. J. Med. Chem. 2018, 62,987-992. [CrossRef] [PubMed]

96. Nguyen, H.S.; Awad, A.J.; Shabani, S.; Doan, N. Molecular Targeting of Acid Ceramidase in Glioblastoma: A Review of Its Role, Potential Treatment, and Challenges. Pharmaceutics 2018, 10, 45. [CrossRef] [PubMed]

97. Doan, N.B.; Alhajala, H.; Al-Gizawiy, M.M.; Mueller, W.M.; Rand, S.D.; Connelly, J.M.; Cochran, E.J.; Chitambar, C.R.; Clark, P.; Kuo, J.; et al. Acid ceramidase and its inhibitors: A de novo drug target and a new class of drugs for killing glioblastoma cancer stem cells with high efficiency. Oncotarget 2017, 8, 112662-74. [CrossRef] [PubMed]

98. Doan, N.B.; Nguyen, H.S.; Al-Gizawiy, M.M.; Jaber, B.; Al-Gizawiy, M.M.; Ahn, E.E.; Mueller, W.M.; Chitambar, C.R.; Mirza, S.P.; Schmainda, K.M.; et al. Acid ceramidase confers radioresistance to glioblastoma cells. Oncol. Rep. 2017, 38, 1932-1940. [CrossRef]

99. Doan, N.B.; Nguyen, H.S.; Montoure, A.; Al-Gizawiy, M.M.; Mueller, W.M.; Kurpad, S.; Rand, S.D.; Connelly, J.M.; Chitambar, C.R.; Schmainda, K.M.; et al. Acid ceramidase is a novel drug target for pediatric brain tumors. Oncotarget 2017, 8, 24753-24761. [CrossRef]

100. Hara, S.; Nakashima, S.; Kiyono, T.; Sawada, M.; Yoshimura, S.; Iwama, T.; Sakai, N. p53-Independent ceramide formation in human glioma cells during gamma-radiation-induced apoptosis. Cell Death Differ. 2004, 11, 853-861. [CrossRef]

101. Chen, J.S.; Chai, M.Q.; Chen, H.H.; Zhao, S.; Song, J.G. Regulation of phospholipase D activity and ceramide production in daunorubicin-induced apoptosis in A-431 cells. Biochim. Biophys. Acta 2000, 1488, 219-232. [CrossRef]

102. Jaffrezou, J.P.; Levade, T.; Bettaieb, A.; Andrieu, N.; Bezombes, C.; Maestre, N.; Vermeersch, S.; Rousse, A.; Laurent, G. Daunorubicin-induced apoptosis: Triggering of ceramide generation through sphingomyelin hydrolysis. EMBO J. 1996, 15, 2417-2424. [CrossRef] [PubMed]

103. Realini, N.; Solorzano, C.; Pagliuca, C.; Pizzirani, D.; Armirotti, A.; Luciani, R.; Costi, M.P.; Bandiera, T.; Piomelli, D. Discovery of highly potent acid ceramidase inhibitors with in vitro tumor chemosensitizing activity. Sci. Rep. 2013, 3, 1035. [CrossRef] [PubMed]

104. Bach, A.; Pizzirani, D.; Realini, N.; Vozella, V.; Russo, D.; Penna, I.; Melzig, L.; Scarpelli, R.; Piomelli, D. Benzoxazolone Carboxamides as Potent Acid Ceramidase Inhibitors: Synthesis and Structure-Activity Relationship (SAR) Studies. J. Med. Chem. 2015, 58, 9258-9272. [CrossRef] [PubMed]

105. Kim, S.W.; Kim, H.J.; Chun, Y.J.; Kim, M.Y. Ceramide produces apoptosis through induction of p27(kip1) by protein phosphatase 2A-dependent Akt dephosphorylation in PC-3 prostate cancer cells. J. Toxicol. Environ. Health A 2010, 73, 1465-1476. [CrossRef] [PubMed]

(C) 2019 by the authors. Licensee MDPI, Basel, Switzerland. This article is an open access article distributed under the terms and conditions of the Creative Commons Attribution (CC BY) license (http://creativecommons.org/licenses/by/4.0/). 